\title{
Browse or Brush? An Exploration of Citizen-Government Interaction in the Municipal Realm
}

\author{
Lisa Schmidthuber \\ Johannes Kepler University Linz \\ lisa.schmidthuber@jku.at
}

\begin{abstract}
To gain a better understanding about new forms of citizen-government interaction enabled by modern technology, we conducted a survey among citizens who interact with their local government by using a web-based platform or a mobile application. In our paper, we investigate the patterns of online and mobile communication between citizens and local government. Based on logistic regressions, we study who possesses the characteristics that predict communication via web and mobile application. Empirical findings indicate that socio-demographic factors (gender, age, education) predict individuals' usage of web over mobile devices. Those with experience in communicating with local government via traditional channels prefer the web interface to get in touch, whereas frequent communicators are more likely to use mobile phone.
\end{abstract}

\section{Introduction}

The emergence of the Internet and the rise of new information and communication technology (ICT) in the 1980s and 1990s have enabled public sector organizations to offer citizens new digital channels to get in touch with public employees, in addition to traditional ones such as front-desk or phone [2]. Electronic government refers to a new form of government's delivery of information and services to the public, business, and public administration electronically [9]. A great number of studies has investigated citizens' participation in e-government, and which factors determine their choice to use technology for contacting government instead of or in addition to offline channels, e.g., [20, 22, 23]. Taking the rise of digital technology in the public sector into account, we intend to go one step beyond and itemize online communication by distinguishing between citizen communication via web page and mobile application with their local government. Whereas prior research on channel choice has focused on traditional and online mediums (i.e. e-government) for citizen-government communications, we

\author{
Dennis Hilgers \\ Johannes Kepler University Linz \\ dennis.hilgers@jku.at
}

investigate online (web-based) and mobile (appbased) communication.

Studying which channels citizens use for communicating with government and which factors determine their decision is important, as organizations are recommended to apply channel management strategies according to citizens' preferences [2]. Understanding which channels citizens prefer for interacting with government is not only essential for stimulating citizen-government communication in general: In the context of the current trend towards opening-up organizational processes to the external environment, externals are encouraged to share their knowledge and experience with government [5, 10, 17]. This collaboration is mainly stimulated by platform-based participation possibilities [6]. Consequently, for promoting open government projects, knowledge on citizens' channel choice might contribute to design open government projects more effectively.

The main objective of this paper is thus to improve our understanding about patterns of citizens' digital channel behavior. In more detail, we aim at analyzing citizens' usage of two digital technologies, web page and mobile application, to interact with government, and explore the factors that determine citizens' decision to communicate via web page or/and mobile phone. Consequently, our research questions read as follows: (1) Which and how many digital channels do citizens use for interacting with government and other citizens? (2) To what extent do socio-demographic criteria, reasons for communication, and communication behavior predict citizens' decision to communicate via computer or/and mobile device with local government? For answering these questions, we conduct a survey among users of a government-initiated platform for citizen participation.

This paper has several contributions: First, we explore the patterns of digital citizen-government interaction by conducting a survey among users communicating with government via website or mobile application. We thereby address the lack of use of primary data in analyzing channel choice [11]. Second, while numerous studies have investigated 
differences of online and offline citizen communication with government, there is very limited research distinguishing between web and mobile app users. We differ from previous research in providing first evidences of differences and similarities in citizens' usage of digital technology to communicate with local government. Third and relatedly, we do not only investigate digital citizengovernment communication, but also consider the effect of citizens' experience in communication via offline and traditional channels (face-to-face, mail, phone) on digital channel choice. Finally, whereas numerous studies on channel choices have focused on one particular country case for conducting research $[20,22,23]$, to our knowledge, there is no research investigating citizens' channel usage in Austria. We take up this point and focus on an Austrian local government citizens communicate with.

\section{Multi-channel government}

Citizens communicate with government on different types of channel [2]. Common channels citizens use for interacting with government or gathering government information are (1) traditional channels, (2) e-government channels, (3) new digital media $[2,24]$.

First, traditional channels of government access are characterized by offline communication via phone or face-to-face. For getting information or services, citizens have to visit a government office or phone public officials. To the contrary, public employees have limited possibilities to inform citizenry, for example, about changed opening hours. With the increase of information and communication technologies, second, digitalization enables government to operate the Internet to exchange information and services with citizens. E-government channels are steadily emerging, which offer information and services 24/7 [9, 19]. Public sector organizations have the possibility to spread information and deliver services to a large number of citizens electronically, and citizens can access to these data and services independent from location and time. Governmental websites provide up-to-date information and citizens can contact public employees easily via mail. Whereas websites, telephone, and front desk were mainly used in the beginning of the 2000s, see e.g., [27], third, the advances of technology enable governments to implement new channels for communication. New digital media include text messaging, social media, and mobile apps. Increasing research has been emerging on these new possibilities to interact and integrate citizens in government [4, 10, 13, 17] Wireless infrastructure allows mobile phone owners to contact public employees via mobile application "on-the-go". Furthermore, social media such as Twitter and Facebook gives governmental organizations the ability to push messages to their followers. Additionally, organizations implement platforms to collaborate with citizens on specific topics, see e.g. [10; 17]. For example, citizens can inform their local government about a broken streetlight directly from the street in real-time (e.g., fixmystreet.com, seeclickfix.com). Furthermore, this innovative and most technology-intensive channel allows not only citizens to communicate with government and vice versa, citizens also have the chance to interact with each other (many-to-many collaboration). Consequently, in the course of this technological development, not only the number of channels citizens can choose to communicate with government has increased, technological innovation also allows to interact and to share information with a greater number of people. Technological advances offer an enhanced level of openness in government. 'Open government' is associated with a new form of collaborating with citizens and a new way of organizing delivery of public services [5]. Next to access to government information, opening up governmental structures involves access to and integration of citizens in decision-making $[3,12]$.

\section{Channel choice and its determinants}

Due to increasing possibilities of citizens to communicate with local government and vice versa, a great stream of literature on factors explaining citizens' use of one channel over another has emerged [11, 21, 22, 24]. A review of prior studies on determinants of channel choice shows that numerous factors influence citizens' decision on how to interact with governmental agencies [21, 22, 24]. Based on these results, we outline three sets of variables in the following which are assumed to influence citizens' decision to communicate via web page or mobile app with local government. As there is, to our knowledge, no prior research on differencing antecedents of web and mobile usage, we do not generate hypotheses, but outline results of studies on channel choice, which are assumed to be relevant in our study.

\subsection{Socio-demographic criteria}

Studies investigating differences in citizen use of digital channels (e.g., e-government) and traditional 
channels for service delivery (i.e., phone, visiting a government office) found that citizens' personal characteristics influence their choice of channel [22]. For example, men use government websites to get services or information from government more often than women $[22,24]$. To the contrary, Pieterson and Ebbers [24] found no significant effect of gender on channel usage. However, age was shown to influence channel usage and choice, in a way, that younger citizens are more likely to use the Internet for government services or acquisition of information [24, 22, 24]. High education is shown to predict using email to contact government [26]. Reddick and Anthopoulus [24] have found that high educated people are more likely to use e-government and new digital media channels. The study conducted by Pieterson and Ebbers [24] also gives evidence that higher education is associated with a higher frequency to use electronic channels. Finally, household increase was shown to positively influence using technology for contacting government [24], so that we can assume association between employment and channel use.

\subsection{Motivation for communication}

In addition to demographic variables, scholars have studied the reasons of channel use. Behavior is shaped by individuals' motivation. In terms of channel usage, individuals' reasons or motivation to get in touch with people influence their choice of technology. Reddick and Turner [22] showed that citizens who use information from their government are more likely to visit government websites. Government websites were also seen as the preferred channel for information retrieval in the study from Pieterson and Ebbers [24]. To the contrary, problemsolving was associated with phone calls [22]. Based on prior results, we expect that reasons and motives for communicating with government (e.g., interest in improving service, "just for fun", altruism) influence citizens' decision on how to get into contact with government.

\subsection{Communication behavior}

As a third set of variables, we assumed that individuals' communication behavior influences their decision on how to communicate with government. First, we add the time of citizens' first use of the platform via web browser or mobile app. Second, we expect the frequency of use to be associated with channel usage. Finally, experience with communicating with government by traditional and offline channels such as phone, mail, or face-to-face might influence citizens' channel choice.

\subsection{Research model}

The analysis of prior literature on channel choice generates a conceptual model outlining various interrelated dependent and independent variables. Figure 1 contains three factors (socio-economic criteria, motivation for communication, communication behavior) to be expected to have an impact on channel selection. These groups of variables are expected to influence individuals' use of the communication channel - three dependent variables (i.e., web usage, mobile usage, multichannel usage). Separate analyses are conducted on predicting individuals' use of a single technology for communication (i.e. Web Site and Mobile Phone) and of multiple channels.

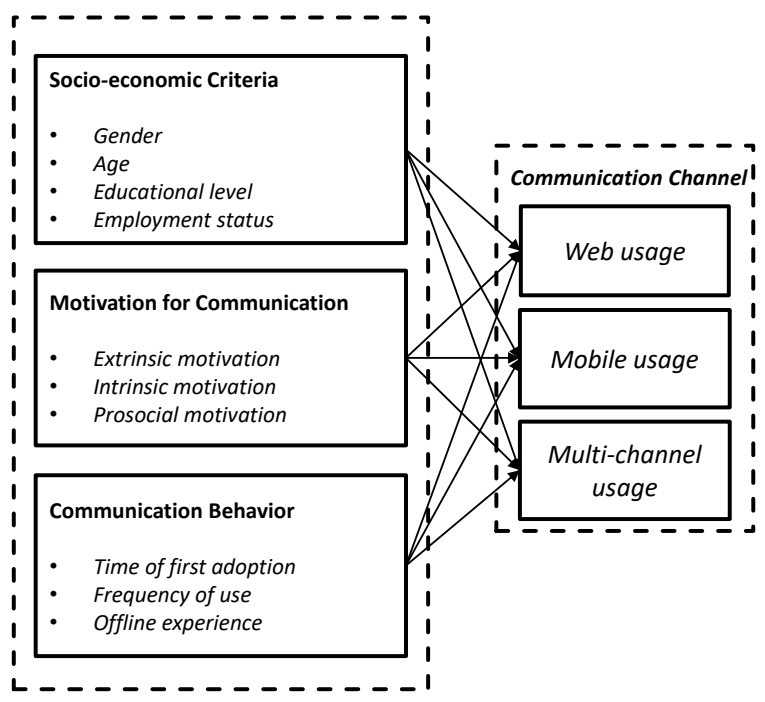

Figure 1. Research model

\section{Research design}

\subsection{Setting and data collection}

Empirical research was conducted by distributing an online survey to citizens who registered on a platform that is meant to stimulate citizengovernment interaction. An Austrian local government has implemented the platform in 2013 and informed citizens about the new possibility to get in touch with administration by various marketing campaigns. The local government intends to strengthen communication and collaboration between citizens and public officials in improving public 
services. Accordingly, citizens are invited to write a report on how to organize public services more efficiently. This particular platform was chosen, as interested citizens can access it by two channels: On the one hand, individuals can open their web browsers, fill out a formula on the web page, and upload a picture. On the other hand, individuals can install an application on their mobile phones (Android and IPhone), which is freely available in the play store. After installing the app, mobile phone users can also write reports, access to and comments on reports on the platform. In both cases, the report is posted on the pinwall and visible to all platform visitors. Public employees who operate the platform and other registered users can comment on the report.

The questionnaire was sent to all registered users of the platform. We received 773 (out of 2,200) completed questionnaires (response rate $35.14 \%$ ). To test for non-response bias, we examined differences be-tween respondents and non-respondents. A t-test showed no significant differences between the two groups.

\subsection{Data analysis}

We use different measures to explore the patterns of digital communication between citizens and local government. First, we conduct descriptive analysis to investigate which and how many digital channels citizens use for interaction and if platform users communicating with different devices differ according to socio-economic criteria, reasons for communication, and communication behavior. We further analyze empirically with t-tests, if web and mobile as well as single-channel users and multichannel users distinguish regarding their frequency of communication and platform activity. Second, we apply binary logistic regression analysis to test our model because our dependent variables (web usage, mobile usage, and multi-channel usage) are dichotomous (usage or non-usage). Results of the logistic regression point to the odds probability of web, mobile, or multi-channel usage based on changes of the explanatory variables. [14].

\subsection{Research methodology and operationalization}

4.3.1. Channel usage. Registered users were asked which device they use to communicate with local government. $58.5 \%$ of respondents (466 individuals) state to use the platform via the Internet, $59.5 \%$ downloaded the application and interact via mobile phones. $18 \%$ of respondents (141 individuals) visit the platform via the Internet and the application. We run three logistic regression analyses with three different dependent variables: (1) web usage versus non-web usage, (2) mobile usage versus non-mobile usage, (3) multi-channel usage versus single-channel usage.

4.3.2. Socio-demographic criteria. For measuring the effect of the digital divide on the decision to communicate with local government via a web page or mobile application, socio-demographic characteristics of platforms users are included into the analysis. Gender was measuring by a dummy variable $($ male $=1$, female $=0$ ), age is measured by three categories $(<29=$ young age, $30-49=$ middle age, $50+=$ old age), and education is distinguished on three levels (low education, middle education, high education). Furthermore, we ask respondents if they have an employment (having employment=1).

4.3.3. Reasons for communication. Based on prior research on platform participation $[1,6,24]$, we included numerous items on motivational variables in the survey to test citizens' reasons for communication. Based on the results of principal component analysis, we distinguish between three types of reasons for platform activity. (1) Intrinsic motivation reflects having fun and enjoyment when being online and using the platform. (2) Prosocial motivation refers to individuals' willingness to contribute to public service improvement and thus communicate with local government and other users for the benefit of the city and citizens. (3) Extrinsic motivation measures the extent to which users perceive a personal benefit when using the platform such as easy and satisfying communication with public officials. For each type of reason, we add up the values of the items and calculate the mean before including in the analysis.

4.3.4. Communication behavior. Three variables capture the communication behavior of platform users. First, the time of first adoption is measured by a categorical variable. Users who first used the platform in the first tertile after implementation are defined as early movers. First adoption in the second tertile after implementation refers to current followers. Those who decided to use the platform after eight months of platform implementation are labelled as late adopters. Second, the frequency of platform use is measured on a five-item Likert scale by asking users how often they visit the platform (5=every day, $4=$ many times a week, $3=$ one a week, $4=$ between one and three times monthly, 1=less often). Third, we ask platform users if they have 
communicated with public officials before the implementation of the platform via traditional and offline channels (i.e. face-to-face, phone, email).

\section{Results}

In the following section, we present the results of our analysis. First, we outline the descriptive results distinguishing by the different groups of platform users. Second, we refer to the results of the multivariate regression analyses.

\subsection{Descriptive results}

5.1.1. Channel usage. The great majority of the sample utilizes one channel for communicating with government $(82.48 \%)$. About half of single-channel users leverage the web browser to interact with public officials, the other half has downloaded the application to get in touch with local government. About 18 per cent of respondents use both the Internet and their mobile phones for communication.

5.1.2. Predictor variables. Table 1 shows the descriptive statistics on predictor variables of those (1) who use the platform via an Internet browser (web usage), (2) who have installed the application and communicate via mobile phone (mobile usage), and (3) who communicate via both channels (multichannel usage).

Table 1. Sample descriptives, Mean (S.D.)

\begin{tabular}{|c|c|c|c|}
\hline & \multicolumn{2}{|c|}{ Single-channel } & \multirow{2}{*}{$\begin{array}{c}\text { Multi-channel } \\
\text { Web \& } \\
\text { Mobile }\end{array}$} \\
\hline & Web & Mobile & \\
\hline \multicolumn{4}{|c|}{ Socio-demographic criteria } \\
\hline Male & $.63(.48)$ & $.74(.44)$ & $.74(.44)$ \\
\hline Employed & $.68(.47)$ & $.76(.43)$ & $.82(.39)$ \\
\hline Young age & $.08(.28)$ & $.30(.46)$ & $.21(.41)$ \\
\hline Middle age & $.38(.49)$ & $.46(.5)$ & $.5(.5)$ \\
\hline Old age & $.54(.5)$ & $.23(.42)$ & $.29(.46)$ \\
\hline Low education & $.25(.44)$ & $.29(.45)$ & $.20(.40)$ \\
\hline Middle education & $.43(.5)$ & $.42(.49)$ & $.36(.48)$ \\
\hline High education & $.32(.47)$ & $.3(.46)$ & $.43(.5)$ \\
\hline \multicolumn{4}{|c|}{ Reasons for participation } \\
\hline Intrinsic & 2.36 & 2.30 & 2.42 \\
\hline motivation & $(.73)$ & $(.76)$ & (.69) \\
\hline Prosocial & 3.56 & 3.58 & 3.65 \\
\hline motivation & $(.51)$ & $(.51)$ & $(.42)$ \\
\hline Extrinsic & 3.22 & 3.32 & 3.32 \\
\hline motivation & $(.67)$ & $(.63)$ & $(.62)$ \\
\hline
\end{tabular}

\begin{tabular}{llll}
\hline & \multicolumn{2}{c}{ Single-channel } & $\begin{array}{c}\text { Multi- } \\
\text { channel }\end{array}$ \\
\hline & Web & Mobile & $\begin{array}{c}\text { Web \& } \\
\text { Mobile }\end{array}$ \\
\hline Communication behavior & & \\
\hline Early movers & $.33(.47)$ & $.38(.49)$ & $.49(.5)$ \\
$\begin{array}{l}\text { Current followers } \\
\text { Late adopters }\end{array}$ & $.25(.43)$ & $.33(.47)$ & $.24(.43)$ \\
$\begin{array}{l}\text { Offline } \\
\text { communication }\end{array}$ & $.46(.5)$ & $.29(.45)$ & $.26(.44)$ \\
$\begin{array}{l}\text { Frequency of } \\
\text { communication }\end{array}$ & 1.9 & $2.45)$ & $.46(.5)$ \\
\hline Observations & $279-314$ & $272-295$ & $121-130$ \\
\hline
\end{tabular}

With regard to socio-economic criteria, descriptive statistics indicate that more male respondents use the platform via the app on their mobile phone. Furthermore, more employed platform users choose the mobile phone to communicate with government. In terms of platform users' age, web users are on average older than mobile users. $54 \%$ of web users and $23 \%$ of mobile users are above 50 . To the contrary, only $8 \%$ of those who use the Internet to enter the platform and $30 \%$ of mobile users are below 30. Platform users are on average medium education. The majority of multi-channel users, however, are high-educated. The survey further asked platform users for which reasons they communicate with administration via the platform. Principal component analysis results in intrinsic, prosocial, and extrinsic motivation of individuals for platform use. As outlined in Table 2, mean values for the three motivational variables do not differ greatly among channel users, so that reasons for communication appear not to have any influence on channel usage.

Finally, results on communication behavior show that majority of web users have started to use the platform eight months after implementation, majority of mobile users and multi-channel users immediately within the first tertile after platform availability. Platform users also reported if they have communicated with local government for making requests via traditional or offline channels. Whereas about $27 \%$ of mobile users have offline experience, about $46 \%$ of web and multi-channel user have contacted public officials for making requests prior to the possibility to interact on the platform. Average multi-channel user uses the platform more frequently than single-channel user.

Table 2 then provides information regarding users' nature of interaction. The survey asked questions on the frequency of platform use and of performing platform activity such as reading reports and comment, commenting on reports, and writing requests. Examining the mean values, average mobile 
users are shown to use the platform more frequently than web users. This difference in frequency of use is statistically significant. Second and with regard to the type of task respondents perform on the platform, results give some indications that mobile users on average use the platform more frequently to read reports and comments than web users. This difference between the two user groups is statistically significant.

Table 2. Nature of interaction of web and mobile users, Mean (S.D.)

\begin{tabular}{|c|c|c|c|}
\hline & \multicolumn{2}{|c|}{ Single-channel user } & \multirow[b]{2}{*}{ T-test } \\
\hline & Web users & Mobile users & \\
\hline $\begin{array}{l}\text { Frequency of } \\
\text { communication }\end{array}$ & $1.9(1.12)$ & $2.17(1.25)$ & $* *$ \\
\hline \multicolumn{4}{|c|}{ Type of platform activity } \\
\hline $\begin{array}{l}\text { Frequency of } \\
\text {... reading } \\
\text {... commenting } \\
\text {... reporting }\end{array}$ & $\begin{array}{l}3.5(1.22) \\
1.68(.83) \\
2.49(.88)\end{array}$ & $\begin{array}{l}3.69(1.19) \\
1.78(.79) \\
2.58(.98)\end{array}$ & * \\
\hline \multicolumn{4}{|c|}{${ }^{+} \mathrm{p}<0.10 ; * \mathrm{p}<0.05 ; * * \mathrm{p}<0.01 ; * * * \mathrm{p}<0.001$} \\
\hline
\end{tabular}

Table 3 illustrates platform activity of singlechannel (web or mobile) and multi-channel users. Descriptive statistics indicate that multi-channel users on average use the platform more frequently and perform all three platform activities to a greater extent. Accordingly, average individuals using the platform with their mobile phones and computers significantly read more reports or comments, comment and write reports more frequently.

Table 3. Nature of interaction of single and multichannel users, Mean (S.D.)

\begin{tabular}{|c|c|c|c|}
\hline & $\begin{array}{l}\text { Single- } \\
\text { channel users }\end{array}$ & $\begin{array}{l}\text { Multi-channel } \\
\text { users }\end{array}$ & T-test \\
\hline $\begin{array}{l}\text { Frequency of } \\
\text { communication }\end{array}$ & $2.03(1.19)$ & $2.54(1.34)$ & $* * *$ \\
\hline \multicolumn{4}{|c|}{ Type of platform activity } \\
\hline $\begin{array}{l}\text { Frequency of } \\
\text {... reading } \\
\text {... commenting } \\
\text {... reporting }\end{array}$ & $\begin{array}{l}3.59(1.21) \\
1.73(.81) \\
2.53(.93)\end{array}$ & $\begin{array}{l}3.89(1.04) \\
2(.85) \\
2.74(.82) \\
\end{array}$ & $\begin{array}{l}* * \\
* * \\
* \\
\end{array}$ \\
\hline \multicolumn{4}{|c|}{${ }^{+} \mathrm{p}<0.10 ;^{*} p<0.05$; $^{* *} p<0.01 ; * * * p<0.001$} \\
\hline
\end{tabular}

\subsection{Multivariate results}

In this section, results on three logistic regressions examining the three sets of predictor variables to determine whether these explain the use of each of the communication channels. Each channel was coded as 1 if respondents used the channel and 0 if it was not used. In case of multi-channel usage, single- channel usage was coded 0 . Tables 4,5 , and 6 report values for the logistic regression equation for predicting the dependent variable from the independent variable including the significance of estimates, the standard errors associated with the coefficient, and the odds ratios for the predictors.

Table 4. Logistic regression on web usage

\begin{tabular}{|c|c|c|c|}
\hline & \multicolumn{3}{|c|}{ Web usage } \\
\hline & B & S.E. & $\begin{array}{l}\text { Odds } \\
\text { ratio }\end{array}$ \\
\hline \multicolumn{4}{|c|}{ Socio-demographic criteria } \\
\hline Male & $-.495^{*}$ & .197 & .610 \\
\hline Employed & .186 & .239 & 1.204 \\
\hline Young age $(<30)$ & $-.643 * *$ & .235 & .525 \\
\hline Middle age (30-50) & Ref & & \\
\hline Old age $(50<)$ & $.703 * *$ & .241 & 2.019 \\
\hline Low education & -.042 & .236 & .959 \\
\hline Middle education & Ref & & \\
\hline High education & $.430 *$ & .212 & 1.538 \\
\hline \multicolumn{4}{|c|}{ Reasons for communication } \\
\hline Intrinsic motivation & .007 & .137 & 1.007 \\
\hline Prosocial motivation & .201 & .205 & 1.222 \\
\hline Extrinsic motivation & -.168 & .150 & .846 \\
\hline \multicolumn{4}{|c|}{ Communication behavior } \\
\hline Early movers & $.451^{*}$ & .223 & 1.57 \\
\hline Current followers & Ref & & \\
\hline Late adopters & $.465^{*}$ & .231 & 1.591 \\
\hline Frequency of use & .001 & .077 & 1.001 \\
\hline Offline participation & $.473^{*}$ & .197 & 1.605 \\
\hline Constant & -.368 & .798 & .692 \\
\hline $\mathrm{N}$ & & 568 & \\
\hline Chi-square & & $58.63 * * *$ & \\
\hline-2 Log likelihood & & 713.82 & \\
\hline Cox \& Snell R square & & .098 & \\
\hline Nagelkerke R square & & .132 & \\
\hline${ }^{+} p<0.10 ; * p<0.05$ & $<0.01 ; *$ & $p<0.001$ & \\
\hline
\end{tabular}

For the socio-demographic variables, findings indicate that men are less likely to use the web for communicating with local government, with an odds ratio of .61. However, male respondents use the applications about two times more likely to interact with government. As the age of respondents rises, they are more likely to use their computers or laptop 
to access the platform. To the contrary, younger platform users install the app on their mobile phones more likely. Finally, high-educated citizens are more likely to browse the web for accessing the platform than those with middle education.

Table 5. Logistic regression on mobile usage

\begin{tabular}{|c|c|c|c|}
\hline & \multicolumn{3}{|c|}{ Mobile usage } \\
\hline & B & SE & $\begin{array}{l}\text { Odds } \\
\text { ratio }\end{array}$ \\
\hline \multicolumn{4}{|c|}{ Socio-demographic criteria } \\
\hline Male & $.703 * * *$ & .197 & 2.02 \\
\hline Employed & .088 & .239 & 1.092 \\
\hline Young age $(<30)$ & $.758^{* *}$ & .272 & 2.134 \\
\hline Middle age (30-50) & Ref & & \\
\hline Old age $(50<)$ & $-.909 * * *$ & .232 & .403 \\
\hline Low education & -.185 & .245 & .831 \\
\hline Middle education & Ref & & \\
\hline High education & -.206 & .217 & .814 \\
\hline \multicolumn{4}{|c|}{ Reasons for communication } \\
\hline Intrinsic motivation & -.026 & .141 & .974 \\
\hline Prosocial motivation & .038 & .208 & 1.039 \\
\hline Extrinsic motivation & .099 & .150 & 1.104 \\
\hline \multicolumn{4}{|c|}{ Communication behavior } \\
\hline Early movers & -.116 & .235 & .891 \\
\hline Current followers & Ref & & \\
\hline Late adopters & $-.458^{+}$ & .237 & .633 \\
\hline Frequency of use & $.254^{* *}$ & .083 & 1.290 \\
\hline Offline participation & -.110 & .199 & .896 \\
\hline Constant & -.542 & .816 & .581 \\
\hline $\mathrm{N}$ & & 568 & \\
\hline Chi-square & & $77.80 * * *$ & \\
\hline-2 Log likelihood & & 686.58 & \\
\hline Cox \& Snell R square & & .128 & \\
\hline Nagelkerke R square & & .173 & \\
\hline${ }^{+} p<0.10 ; * p<0.05$ & $<0.01 ; * * *$ & $p<0.001$ & \\
\hline
\end{tabular}

As far as reasons for communication are concerned, empirical investigation shows that respondents' motivation to use the platform do not predict their channel choice. Results of all three regression analysis are insignificant.

Lastly, communication behavior appears to predict channel choice. Accordingly, early adopters as those respondents who have started to use the platform immediately after its implementation are more likely to access via their web browsers $(\mathrm{OR}=1.57)$. Similar holds true with regard to multichannel users $(\mathrm{OR}=1.71)$. Whereas current followers are more likely to use the app for communication, late adopters utilize the web more likely. Those respondents who have reported to use the platform frequently are more likely to communicate via app $(\mathrm{OR}=1.29)$ or use more channels for interacting $(\mathrm{OR}=1.401)$. As a further finding, analyses indicate that respondents with offline experience in communication with local government due to requests were more likely to use the web page $(\mathrm{OR}=1.61)$ or more channels $(\mathrm{OR}=1.7)$.

Table 6. Logistic regression on multi-channel usage

\begin{tabular}{|c|c|c|c|}
\hline & \multicolumn{2}{|c|}{ Multi-channel usage } & \multirow[b]{2}{*}{$\begin{array}{l}\text { Odds } \\
\text { ratio }\end{array}$} \\
\hline & B & SE & \\
\hline \multicolumn{4}{|c|}{ Socio-demographic criteria } \\
\hline Male & .322 & .254 & 1.38 \\
\hline Employed & .42 & .333 & 1.52 \\
\hline Young age $(<30)$ & -.099 & .301 & .91 \\
\hline Middle age (30-50) & Ref & & \\
\hline Old age $(50<)$ & -.427 & .308 & .65 \\
\hline Low education & -.343 & .321 & .71 \\
\hline Middle education & Ref & & \\
\hline High education & .388 & .262 & 1.47 \\
\hline \multicolumn{4}{|c|}{ Reasons for communication } \\
\hline Intrinsic motivation & .009 & .175 & 1.009 \\
\hline Prosocial motivation & .4 & .294 & 1.492 \\
\hline Extrinsic motivation & -.119 & .193 & .888 \\
\hline \multicolumn{4}{|c|}{ Communication behavior } \\
\hline Early movers & $.534^{+}$ & .285 & 1.71 \\
\hline Current followers & Ref & & \\
\hline Late adopters & .028 & .318 & 1.02 \\
\hline Frequency of use & $.337^{* * *}$ & .094 & 1.40 \\
\hline Offline participation & $.528^{*}$ & .24 & 1.7 \\
\hline Constant & $-4.32 * * *$ & 1.14 & .01 \\
\hline $\mathrm{N}$ & & 568 & \\
\hline Chi-square & & $41.7^{* * *}$ & \\
\hline-2 Log likelihood & & 496.10 & \\
\hline Cox \& Snell R square & & .071 & \\
\hline Nagelkerke R square & & .116 & \\
\hline${ }^{+} p<0.10 ; * p<0.05$ & $0<0.01 ; * *$ & $<0.001$ & \\
\hline
\end{tabular}




\section{Discussion, implications and future research}

\subsection{Discussion}

This study investigates the patterns of citizengovernment interaction by leveraging modern technology. Based on the results of a citizen survey, we explore citizen communication with local government by utilizing the Internet or/and a mobile application. The study found some interesting results that are worth reviewing. First, the great majority of sample respondents use one digital channel to interact with government. Haft of them use the Internet, half of them have installed the mobile app and communicated via mobile phone. About 18 per cent of the sample take up both the web and the app for communicating with government.

Second, distinguishing between web and mobile users, results show that those having installed the app on average communicate with government more frequently via their mobile phones than web users do. Whereas the intensity of active contributions (i.e. writing comments or reports) do not differ significantly, it is shown that mobile users use the platform more frequently passive by reading reports and comments. In terms of single versus multichannel usage, findings indicate that multi-channels on average conduct all kinds of platform activity more frequently than single-channel users.

Third, socio-demographic criteria of platform users appear to predict their digital channel choice. Similar to the differences in personal characteristics of online and offline participation [24, 26, 24], women and older people tend to use the web browser for communication. To the contrary, men and younger respondents answered to use the mobile phone more likely. However, high education is associated with web usage.

Fourth, individual communication behavior is shown to influence the decision on how to communicate with government. The time of first adoption, frequency of use, and experience in offline communication predict participants' channel usage. Accordingly, those who decided to use the platform immediately after implementation (first movers) tend to use the web browser or both channels. Citizens with frequent communication behavior are more likely to interact mobile or use both channels. Lastly, individuals who have already contacted local government via traditional and offline channels for requests are more likely to communicate by using the web browser or both channels.
To sum up, the findings of this study show that personal characteristics influence digital channel usage and thus certain group of citizens prefers one channel over another.

\subsection{Implications}

The advances of technology and the increasing use of new digital media have stimulated the emergence of a new approach encouraged by the public sector to improve citizen-government interaction. An increased level of openness does not only allow externals to get access to government information, but also enable new forms of collaborations between government organizations and external actors such as citizens, business, or universities. Going beyond a dyadic communication, the use of platforms, forums, and social media leads to the evolution of a new form of interaction between multiple stakeholders. Whereas in previous times, for example, local government was not able to fix broken street-lights until they have identified the problems themselves, platform-based collaboration between citizens and government enables a new division of labor and organizing public service delivery. People detecting a problem or defect on the streets inform a public employee via leveraging technology. With the help of proactive individuals, government can fix infrastructural defects more quickly, as they get access to citizens' knowledge.

The results of our study on how citizens provide administration access to their knowledge show that people with different socio-demographic characteristics, motives, and communication behavior prefer to communicate with administration via a different number and type of channels. These findings imply that research on open government and new forms of collaboration between different kinds of groups can learn from literature on 'digital divide'. The 'digital divide' stresses inequalities in providing access and using the Internet in society [16]. The degree of access to Internet and technology depends on ethnicity, income, age, and education [26]. Accordingly, being white, wealth, young age, and better education are not only associated to Internet use in general, but also to making use of online governmental information. Furthermore, skills, particularly technology competence and information literacy [15], are required to effectively use technology and thus engage in platform-based communication. Research on digital divide has made clear that there is no homogenous citizenry government has to serve [4]. Instead of "the citizens", people with different demographics, needs, and expectations try to interact with government. This 
implies that it is not possible to address all citizens with one system or channel [4].

These findings further lead to managerial implications for local governments: Platform and user diversity calls for different measures to address the needs of citizens and an improved understanding on how to integrate them into the platform community. To provide participation and communication possibilities for all citizens, we recommend offering channel diversity to governmental organizations, thus applying a multichannel strategy. Providing multiple channels for communications is further shown to increase communication and interaction frequency.

\subsection{Limitations and directions for future research}

In spite of various contributions discussed above, this study has limitations. This paper focuses on citizens' communication with two digital channels (web browser and mobile app), and provides first evidences for individuals' usage of these innovative digital technologies to interact with government and its determinants. Whereas this study compares mobile and web users as well as single-channel and multichannel users and study the effect of offline communication experience, we do not include those citizens who only use traditional and offline channels to get in touch with government. Differencing between offline, online, and mobile communications would shed further light on citizens' channel choice and support public sector organizations in choosing their channel management strategies.

In addition to extending the sample, future researchers are well-advised to further investigate citizen use of digital technology to communicate with government and add more variables to the analysis. For example, scholars can ask citizens about their satisfaction with the channel service and consider channel use evaluation $[22 ; 25]$.

Another avenue for future research would be to apply other research methods to study digital channel usage (e.g., case studies, experiments, cross-country analysis), and to verify our results by questioning citizens who communicate with government via digital channels for other reasons and in another context.

Finally, whereas this study concentrates on the antecedents of channel usage, we need research on the outcomes of citizen communication via multiple channels. On the individual level, it has to be studied if the provision or usage of certain channels is associated with an increase in citizen satisfaction with service provision and delivery, and with employees' level of public service motivation and administrative burden. On the organizational level, it would be interesting to investigate the effectiveness and efficiency of employing a great number and certain forms of channels for communication with citizens.

\section{References}

[1] Davis, F. D., Bagozzi, R. P., \& P. R. Warshaw. (1989). User acceptance of computer technology: A comparison of two theoretical models. Management Science, 35(8), 9821003.

[2] Ebbers, W. E., Pieterson, W. J., \& H. N. Noordman. (2008). Electronic government: Rethinking channel management strategies. Government Information Quarterly, 25(2), 181-201.

[3] Evans, A. M., \& A. Campos. (2013). Open government initiatives: Challenges of citizen participation. Journal of Policy Analysis and Management, 32(1), 172203.

[4] Helbig, N., Gil-García, J. R., \& E. Ferro. (2009). Understanding the complexity of electronic government: Implications from the digital divide literature. Government Information Quarterly, 26(1), 89-97.

[5] Hilgers, D. (2012). Open Government: Theoretische Bezüge und konzeptionelle Grundlagen einer neuen Entwicklung in Staat und öffentlichen Verwaltungen. Zeitschrift für Betriebswirtschaft, 82(6), 631-60.

[6] Hilgers, D. \& C. Ihl. (2010). Citizensourcing: Applying the concept of open innovation to the public sector. The International Journal of Public Participation, $4(1), 67-88$.

[7] Kernaghan, K. (2013). Changing channels: Managing channel integration and migration in public organizations. Canadian Public Administration, 56(1), 121-141.

[8] Kube, M., Hilgers, D., Koch, G. \& J. Füller. (2015). Explaining voluntary citizen online participation using the concept of citizenship: An explanatory study on an open government platform. Journal of Business Economics, 85(8), 873-895.

[9] Lee, H., Irani, Z., Osman, I. H., Balci, A., Ozkan, S., \& T. D. Medeni. (2008). Research note: Toward a reference process model for citizen-oriented evaluation of e-government services. Transforming Government: People, Process and Policy, 2(4), 297-310.

[10] Linders, D. (2012). From e-government to wegovernment: Defining a typology for citizen coproduction in the age of social media. Government Information Quarterly, 29(4), 446-454. 
[11] Madsen, C. Ø., \& P. Kræmmergaard. (2015). Channel Choice: A Literature Review. In Electronic Government (pp. 3-18). Springer International Publishing.

[12] Meijer, A., Curtin, D., \& M. Hillebrandt. (2012). Open government: Connecting vision and voice. International Review of Administrative Sciences, 78(1), 10-29.

[13] Mergel, I. (2015). Open collaboration in the public sector: The case of social coding on GitHub. Government Information Quarterly, 32(4), 464-472.

[14] Mertler, C. A., \& R. A. Vannatta. (2002). Advanced and multivariate statistical methods. Los Angeles, CA: Pyrczak.

[15] Mossberger, K., Mary, K., Tolbert, C. J. \& M. Stansburg. (2003). Virtual inequality: Beyond the digital divide. Georgetown University Press.

[16] Mossberger, K., Tolbert, C. J., \& R. S. McNeal. (2007). Digital Citizenship: The Internet, Society, and Participation. Cambridge, MA: MIT Press.

[17] Nam, T. (2012). Suggesting frameworks of citizensourcing via Government 2.0. Government Information Quarterly, 29(1), 12-20.

[18] Nam, T., \& T. A. Pardo. (2014). Understanding Municipal Service Integration: An Exploratory Study of 311 Contact Centers. Journal of Urban Technology, 21(1), 57-78.

[19] Norris, D. F., Fletcher, P. D., \& S. H. Holden. (2001). Is your local government plugged in? Highlights of the 2000 electronic government survey. Washington, DC: International City/County Management Association.

[20] Pieterson, W., \& W. Ebbers. (2008). The use of service channels by citizens in the Netherlands: Implications for multi-channel management. International Review of Administrative Sciences, 74(1), 95-110.

[21] Pieterson, W., \& J. Van Dijk. (2007). Channel Choice Determinants; An exploration of the factors that determine the choice of a service channel in citizen initiated contacts. In Proceedings of the 8th Annual International Conference on Digital government research: Bridging Disciplines \& Domains (pp. 173-182). Digital Government Society of North America.

[22] Reddick, C. G., \& M. Turner. (2012). Channel choice and public service delivery in Canada: Comparing egovernment to traditional service delivery. Government Information Quarterly, 29(1), 1-11.

[23] Reddick, C. G., Abdelsalam, H. M., \& H. A. Elkadi. (2012). Channel choice and the digital divide in egovernment: the case of Egypt. Information Technology for Development, 18(3), 226-246.
[24] Reddick, C., \& L. Anthopoulos. (2014). Interactions with e-government, new digital media and traditional channel choices: citizen-initiated factors. Transforming Government: People, Process and Policy, 8(3), 398-419.

[25] Teerling, M. L., \& W. Pieterson. (2011). How to improve e-government use: An empirical examination of multichannel marketing instruments. Information Polity, 16(2), 171-187.

[26] Thomas, J. C. \& G. Streib. (2003). The new face of government: citizen-initiated contacts in the era of egovernment. Journal of Public Administration Research and Theory, 13(1), 83-102.

[27] Van Deursen, A., \& W. Pieterson. (2006). The Internet as a service channel in the Public Sector. In ICA Conference, Dresden, Germany.

[28] Wijnhoven, F., Ehrenhard, M. \& J. Kuhn. (2015). Open government objectives and participation motivations. Government Information Quarterly, 32(1), 30-42. 